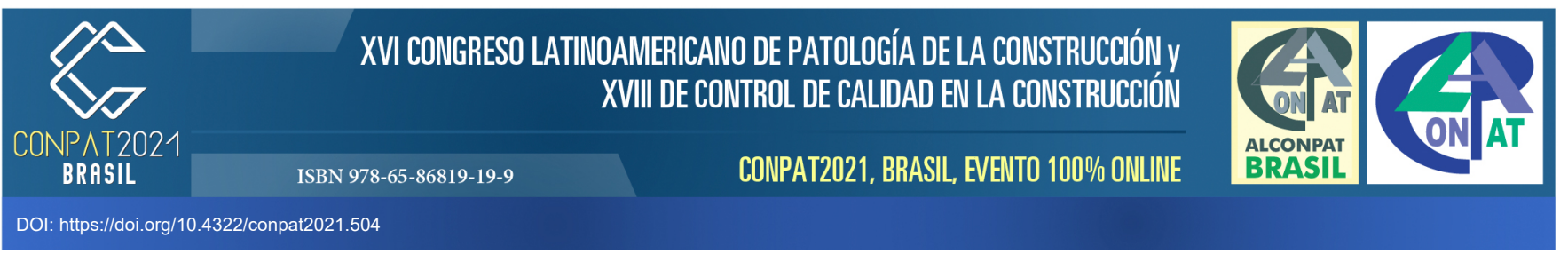

\title{
Análise comparativa entre os métodos de tração simples e de cisalhamento para avaliação de desempenho mecânico de um composto polimérico de dispersão aquosa para assentamento de pisos e revestimentos de paredes
}

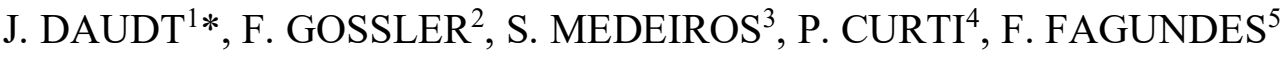 \\ *Autor de Contato: julio.daudt@fcc.com.br
}

${ }^{1}$ Engenheiro, M.Sc., Universidade do Vale do Rio dos Sinos, São Leopoldo, Brasil.

${ }^{2}$ Química, M.Sc, Universidade Federal do Rio Grande do Sul, São Leopoldo, Brasil.

${ }^{3}$ Graduando em Engenharia, Centro Universitário e Faculdades UNIFTEC, Sapiranga, Brasil.

${ }^{4}$ Engenheiro, MBA, Centro Universitário FEI, São Paulo, Brasil.

${ }^{5}$ Químico, M.Sc., Universidade Federal do Rio Grande do Sul, Novo Hamburgo, Brasil.

\section{RESUMO}

Cada vez mais os desplacamentos em revestimentos tornam-se um problema social e financeiro bastante significativo. Este trabalho tem o objetivo de explorar as diferenças entre os fenômenos de tração simples e cisalhamento nos eventos de desplacamentos e avaliar os métodos de medição de desempenho mecânico em compostos poliméricos de dispersão aquosa. Fez-se a avaliação de resistência à tração simples por meio de métodos previstos para materiais cimentícios e avaliação de resistência ao cisalhamento em ensaios laboratoriais em um composto polimérico. Os resultados indicam que os métodos para análise de materiais cimentícios não devem ser os mais adequados para avaliação de materiais flexíveis como adesivos de dispersão aquosa, e que o fenômeno de cisalhamento é o mais atuante em desplacamentos.

Palavras-chave: revestimentos, desplacamentos; composto polimérico; tração simples; cisalhamento. 


\section{INTRODUÇÃO}

As manifestações patológicas em pisos e revestimentos de paredes internas ainda são problemas que persistem nas edificações, mesmo com o avanço das tecnologias associadas aos materiais e às técnicas executivas desses revestimentos. Dentre as principais manifestações patológicas associadas, uma das mais evidentes é o desplacamento cerâmico. (BAUER et al., 2011; MELO et al., 2020; SOUZA et al., 2018). Segundo a Câmara Brasileira da Indústria da Construção (CBIC, 2019), foram mais de 2,6 milhões de $\mathrm{m}^{2}$ de revestimentos desplacados no Brasil entre 2015 e 2019.

No Brasil, a principal metodologia de avaliação de desempenho dos sistemas de revestimento em termos de desplacamentos, principalmente das argamassas colantes, é a determinação de resistência de aderência em tração simples de amostras, segmentadas diretamente no piso ou revestimento de parede instalados (SAGAVE, 2001; SILVA, 2018). Entretanto, essa metodologia pode não ser suficiente para essa avaliação, visto que a aderência do sistema é resultante também da parcela de resistência ao cisalhamento nas interfaces entre os materiais e na estrutura desses próprios materiais.

O material que tem a função de aderir as peças cerâmicas e porcelanatos ao substrato é a argamassa colante, que mais comumente é industrializada e necessita de mistura com água in situ. Ainda em seu estado fresco é caracterizada por boa trabalhabilidade, entretanto, como é de base cimentícia é um material que atua majoritariamente provendo aderência mecânica entre os materiais e que após o período de cura apresenta um comportamento rígido frente às solicitações existentes, tanto em termos de esforço normal quanto cisalhante (WETZEL et al., 2012).

A argamassa colante é uma mistura de areia, cimento, aditivos químicos e água, classificada em três grupos no mercado brasileiro: ACI, ACII e ACIII. A primeira categoria é indicada para ambientes internos em revestimentos cerâmicos; a segunda para ambientes externos de peças cerâmicas; o terceiro grupo é indicado para condições mais críticas, em que se aplica também porcelanatos, áreas quentes e fachadas (ASSOCIAÇÃO BRASILEIRA DE NORMAS TÉCNICAS, 2012; OLIVEIRA et al., 2019; SASSAKI, 2017).

Novos materiais vêm surgindo no mercado, muitos ainda com base cimentícia e adição de material polimérico para promover uma redução de rigidez (OLIVEIRA et al., 2019). Materiais sem cimento em sua composição também estão sendo inseridos e entregam um desempenho diferente das argamassas colantes rígidas. Os adesivos de dispersão aquosa, por exemplo, vêm prontos para aplicação, sem a necessidade de realizar mistura com água in situ, e funcionam com base tecnológica e conceitual em que dependem da expulsão da água (secagem) da matriz para promoverem a aderência entre as peças e o substrato. Diferentemente de materiais cimentícios, em que após o tempo de pega a água favorece as reações de formação dos compostos resistentes do cimento, consequentemente da matriz, por meio da cura (MEHTA; MONTEIRO, 2014).

Segundo a ISO 13007 (INTERNATIONAL STANDARD ORGANIZATION, 2014), esses compostos poliméricos de dispersão aquosa são misturas de água, resina polimérica, carga mineral e aditivos químicos especiais, em geral. Caracterizam-se majoritariamente pela parcela de aderência química que promovem entre os materiais do sistema, e são flexíveis após o processo de expulsão da água (secagem). Alguns fabricantes afirmam que a flexibilidade de seus compostos sem cimento é de 35 vezes superior aos materiais colantes cimentícios, segundo a metodologia de determinação de flexibilidade da EN 12002 (BS, 2008). 
As NBR 13753 e NBR 13754 (ABNT, 1996), que são as normas brasileiras que prescrevem os métodos e critérios para aceitação de revestimentos de pisos e paredes em ambientes internos, determinam em seu Anexo A que o princípio da determinação da resistência de aderência é dado pela "... aplicação de uma força de tração simples normal, aplicada em uma pastilha metálica colada no corpo de prova...". Entretanto, como mostraram Bauer e Rago (2001), Cincotto et al (1995) e Sagave (2001), o fenômeno de cisalhamento é o principal esforço atuante no sistema, solicitação não contemplada no ensaio previsto pelas normas brasileiras. A Figura 1 mostra uma representação esquemática comparativa entre essas solicitações mecânicas atuantes.

Figura 1: representação esquemática de esforços solicitantes nos sistemas de revestimento.

(a) Esforço de tração simples

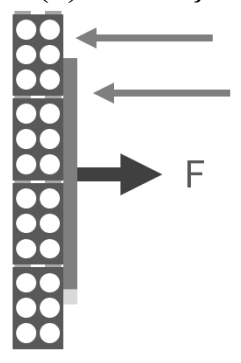

\section{Alvenaria \\ Sistema de \\ Revestimento}

(b) Esforço de cisalhamento

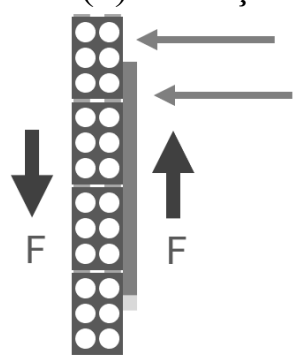

Alvenaria

Sistema de Revestimento

Fonte: elaborado pelos autores.

O método de tração simples prevê a aplicação de uma força de arrancamento perpendicular ao plano da alvenaria. Já o método prescrito pela ISO 13007 (ISO, 2014) para compostos poliméricos de dispersão aquosa, em que aplica-se um esforço de cisalhamento na interface entre placas aderidas por meio do material, o esforço cortante predominante em sistemas construídos é contemplado na avaliação experimental, a partir da aplicação de uma força tangencial ao plano do revestimento. Essa norma define a resistência de aderência como "a máxima força por unidade superficial de área que pode ser medida por um teste de cisalhamento ou tração".

Llorens et al. (2020), Silva (2018) e Souza et al. (2018) dizem que a principal causa de desplacamentos cerâmicos registrados nas edificações é a formação de fissuras no material colante utilizado para aderência do revestimento ao substrato, dadas majoritariamente pelos esforços de cisalhamento na interface. Essas solicitações cortantes são provenientes de inúmeros fatores, que podem atuar isolada ou complementarmente sobre o sistema de revestimento. Expansão por umidade e retração hidráulica dos materiais são dois desses fatores.

Pode-se dizer que dentre todos os fatores que geram a solicitação de cisalhamento os principais são a dilatação térmica diferencial e a movimentação dinâmica diferencial entre os materiais componentes do sistema. A dilatação térmica diferencial ocorre porque a cerâmica, o material colante e o substrato possuem coeficientes de dilatação térmica diferentes entre si, e com a exposição do sistema formado às condições climáticas de variação de umidade relativa e variação de temperatura ambiente e entre ambientes essas dilatações ocorrem. A movimentação dinâmica diferencial pode-se dar por aplicação de carregamentos não distribuídos linearmente nas estruturas, ação de vento, recalques diferenciais ou acomodação geral dos diferentes sistemas de uma edificação (LOURENÇO et al., 2017; WINNEFELD et al., 2012). Nesses dois fatores, exceto em casos excepcionais, não é possível verificar um esforço de tração simples atuante, somente de cisalhamento e torção, que se enquadra no esforço de cisalhamento quando aplicada paralelamente entre dois planos significativamente próximos um do outro. 
Este trabalho, portanto, se insere em um contexto de avaliação de resultados de ensaios de tração simples e de cisalhamento para um composto polimérico de dispersão aquosa. Tem como objetivo verificar qual método é mais adequado para avaliação desses compostos entre os dois e avaliar se as abordagens das normas brasileiras vigentes podem ser aplicadas à materiais não cimentícios.

\section{MATERIAS E MÉTODOS}

Neste item do trabalho estão sendo apresentados os materiais utilizados na pesquisa e os métodos avaliados no trabalho.

\subsection{Materiais}

\subsubsection{O Composto Polimérico de Dispersão Aquosa}

O composto polimérico a base de dispersão aquosa utilizado neste estudo foi o produto DunDun Cerâmica do fabricante FCC Química, composto basicamente por resina polimérica, cargas minerais, aditivos químicos e água. A massa específica desse produto é dada entre 1,72 a 1,98 $\mathrm{g} / \mathrm{cm}^{3}$, conforme NBR 8916 (ABNT, 2020). Sua consistência foi medida através da metodologia da norma BS 4551 (BRITISH STANDARD, 2013), por Dropping Ball, apresentando faixa entre 5,0 a $8,0 \mathrm{~mm}$. O teor de sólidos apresentou-se, conforme a NBR 8877 (ABNT, 2015), na faixa entre $75 \%$ e $85 \%$, e pH entre 8 e 10 medido através de papel padrão de indicador de $\mathrm{pH}$.

\subsubsection{Os Substratos Cerâmicos}

Os substratos cerâmicos utilizados nos ensaios foram de dois grupos, classificados conforme a ISO 13006 (ISO, 2020): grupo BIIa para os testes conforme a norma NBR 14081 (ABNT, 2012, que trata-se do método de tração simples e do grupo BIII para os testes conforme a ISO 13007 (ISO, 2014), que trata-se do método de cisalhamento.

Os corpos de prova cerâmicos do tipo BIIa são classificados como semi-porosos e com classificação de faixa de absorção de água de 3\% a 5\%. Foram produzidos com dimensões aproximadas de 5,0 x 5,0 x 0,75 cm conforme a NBR 14081 (ABNT, 2012).

Os corpos de prova cerâmicos do tipo BIII, os quais são classificados como porosos, com faixa de absorção especificada entre $15 \%$ e $19 \%$, foram preparados com as dimensões aproximadas de 10,8 x 10,8 x 0,6 cm, conforme prescrito pela ISO 13007 (ISO, 2014).

\subsubsection{As Placas de Substrato Padrão para Ensaios segundo a NBR 14081:2012}

Para o método de tração simples utilizaram-se as placas de substrato padrão para ensaio de argamassa fabricado de acordo com a NBR 14081 (ABNT, 2014), do fabricante Associação Brasileira de Cimento Portland (ABCP) e nas dimensões de 25 x 50 x 4,0 cm.

\subsection{Métodos}

\subsubsection{Cisalhamento Segundo a ISO 13007:2014}

Os ensaios realizados de acordo com a ISO 13007 (ISO, 2014) foram executados atendendo aos requisitos da categoria D1, para adesivos de dispersão aquosa (D) e adesivo normal (classe 1), para 
ambientes internos. Os ensaios que compõem a categoria D1 são: secagem em temperatura ambiente com especificação mínima de resistência ao cisalhamento de 1,0 MPa e de secagem com aquecimento em estufa, sendo o requisito mínimo de 1,0 $\mathrm{MPa}$. Ainda foram realizados ensaios de cisalhamento para o método de secagem em temperatura ambiente e posterior imersão em água, para comparação de resultados com os métodos da NBR 14081 (ABNT, 2012), em que o requisito dado é para categoria D2, de 0,5 MPa, já para adesivos de dispersão aquosa para ambientes externos.

\subsubsection{Preparação dos Corpos de Prova}

A preparação dos corpos de prova foi realizada conforme descrito na ISO 13007 (ISO, 2014). Neste método são utilizados substratos cerâmicos do grupo de absorção BIII e a aplicação do produto foi realizada a partir de um molde com medidas padrões definido pela referida norma, conforme representado na Figura 2 (a). O corpo de prova é formado pela união da face cerâmica com produto aplicado e outra sem aplicação, conforme demostrado na Figura 2 (b) e (c).

Figura 2: preparação dos corpos de prova para cisalhamento segundo a ISO 13007 (ISO, 2014). (a) ilustração da aplicação do adesivo, (b) aplicação realizada do adesivo e (c) corpo de prova finalizado.

(a)

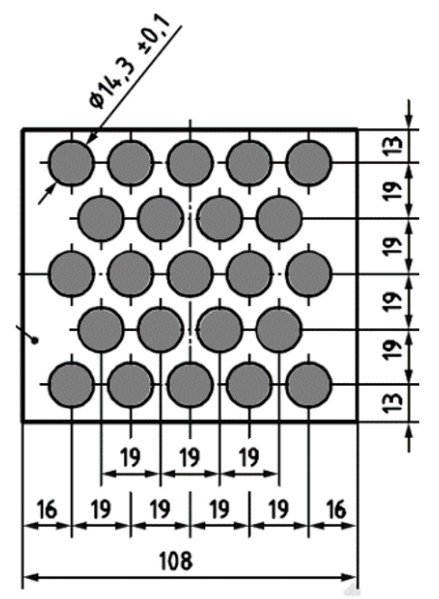

(b)

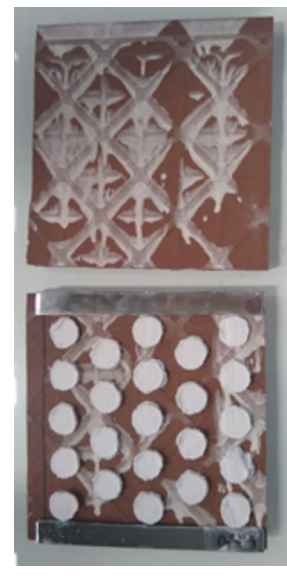

(c)

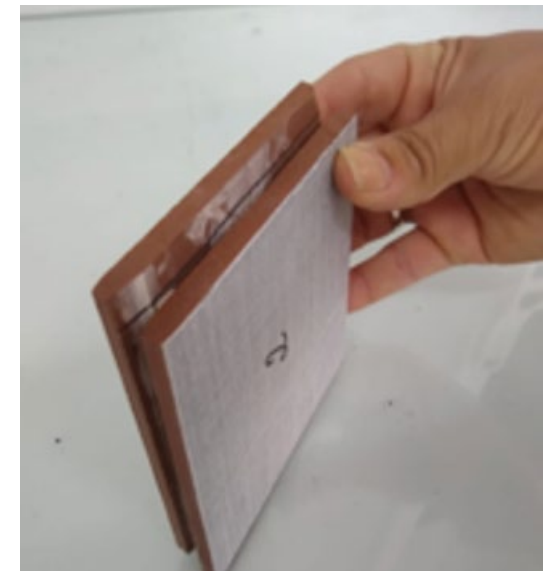

Fonte: adaptado de ISO 13007 (ISO, 2014) e elaborado pelos autores.

Foram preparados 10 corpos de prova para cada condição de secagem e acondicionados conforme requisitos de cada condição, descritos na Tabela 1.

Tabela 1: condições de secagem e exposição avaliadas

\begin{tabular}{lccc}
\hline $\begin{array}{l}\text { Método de } \\
\text { Secagem/Exposição }\end{array}$ & $\begin{array}{c}\text { Secagem Ambiente } \\
23^{\circ} \mathrm{C}+/-2{ }^{\circ} \mathrm{C} \text { e U.R. } \\
60 \%\end{array}$ & $\begin{array}{c}\text { Secagem Temperatura } \\
\text { Elevada } 70^{\circ} \mathrm{C}+/-2{ }^{\circ} \mathrm{C}\end{array}$ & $\begin{array}{c}\text { Imersão em Água } 23^{\circ} \mathrm{C} \\
+/-2{ }^{\circ} \mathrm{C}\end{array}$ \\
\hline $\begin{array}{l}\text { Temperatura Ambiente } \\
\begin{array}{l}\text { Temperatura Ambiente }+ \\
\text { Temperatura Elevada }\end{array}\end{array}$ & 14 dias & - & - \\
\hline $\begin{array}{l}\text { Temperatura Ambiente }+ \\
\text { Imersão em Água }\end{array}$ & 21 dias & 14 dias & 7 dias \\
\hline
\end{tabular}

Fonte: elaborado pelos autores. 
Nota-se que o método de secagem ambiente com posterior imersão em água é um método prescrito para adesivos de dispersão aquosa a serem aplicados em ambientes externos. Foi realizado para comparação com método de tração simples indicado para materiais cimentícios.

\subsubsection{Tração Simples segundo a ABNT NBR 14081:2012}

Os ensaios de tração simples em arrancamento da NBR 14081 (ABNT, 2012) foram realizados com as definições de argamassa do tipo ACII por similaridade de aplicação, visto esta norma não possuir requisitos para a tecnologia de adesivos de dispersão aquosa, que é o caso do composto polimérico avaliada neste estudo. Os ensaios que compõem a classificação ACII são: cura normal, cura com imersão em água e cura com aquecimento em estufa com especificação mínima de 0,5 $\mathrm{MPa}$.

\subsubsection{Preparação dos Corpos de Prova}

A preparação dos corpos de prova foi realizada conforme descrito na NBR 14081 (ABNT, 2012). A aplicação do composto polimérico foi realizada sobre o substrato padrão pelo processo de imprimação, demonstrado na Figura 3 (a), onde porções do composto foram colocadas sobre a face rugosa do substrato e estendidas com o lado liso da desempenadeira num movimento de vaivém apoiado firmemente sobre a superfície. Após, novas porções do composto foram colocadas e estendidas com quantidade suficiente para a formação dos cordões de altura de $8 \pm 0,5 \mathrm{~mm}$ realizados com o lado dentado da desempenadeira, conforme Figura 3 (b).

Figura 3: preparação dos corpos de prova para tração simples segundo a ABNT NBR 14081 (2012). (a) imprimação e (b) formação dos cordões com desempenadeira dentada

(a)

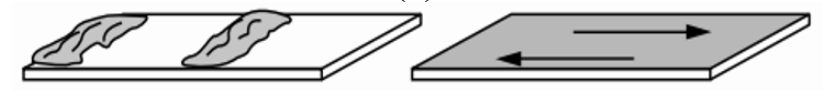

Fonte: adaptado de NBR 14081 (ABNT, 2012) (b)

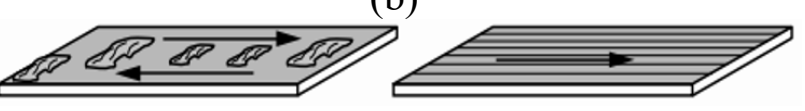

Após transcorrido 5 minutos da aplicação foram posicionadas 10 placas cerâmicas de lados $5 \mathrm{~cm}$ do grupo de absorção BIIa. As amostras foram acondicionadas conforme requisitos de cada processo de secagem, conforme descritos nos itens 2.2.2.2, 2.2.2.3 e 2.2.2.4. Com 72 horas antes de finalizar os processos de secagem, as pastilhas metálicas foram coladas com adesivo epóxi sobre as peças cerâmicas, para realização dos ensaios de tração simples em arrancamento com equipamento Pull-Off do fabricante Solotest.

\subsubsection{Secagem em Temperatura Ambiente}

Os corpos de prova foram submetidos pelo período de 28 dias nas condições de temperatura 23 $\pm 2{ }^{\circ} \mathrm{C}$ e $60 \pm 2 \%$ de UR.

\subsubsection{Secagem em Temperatura Ambiente e Posterior Exposição à Temperatura Elevada}

Os corpos de prova foram submetidos pelo período de 14 dias nas condições de temperatura 23 $\pm 2{ }^{\circ} \mathrm{C}$ e $60 \pm 2 \%$ UR e após essa etapa foram colocados em estufa à temperatura de $70 \pm 2^{\circ} \mathrm{C}$ por mais 14 dias. Faltando 72 horas para finalizar o processo de secagem foi retirado o conjunto da estufa e realizado a colagem das placas metálicas com adesivo epóxi sobre os corpos de prova 
cerâmicos. Após 24 horas, o conjunto foi disposto novamente na estufa e dado continuidade no ensaio.

\subsubsection{Secagem em Temperatura Ambiente e Posterior Imersão em Água}

Os corpos de prova foram submetidos pelo período de 21 dias nas condições de temperatura 23 $\pm 2{ }^{\circ} \mathrm{C}$ e $60 \pm 2 \%$ UR e após essa etapa foram imersos em água na condição de $23 \pm 2{ }^{\circ} \mathrm{C}$ por 7 dias. Faltando 72 horas para finalizar o teste foi retirado o conjunto da imersão e realizada a colagem das pastilhas metálicas com adesivo epóxi. Após 24 horas para secagem do adesivo epóxi o conjunto foi disposto novamente à imersão. O teste de arrancamento foi realizado após mais 48 horas nas condições de imersão.

\subsubsection{Tração Simples segundo as ABNT NBR 13753:1996 e NBR 13754:1996}

As únicas normas técnicas nacionais que preveem uma metodologia para avaliação de desempenho mecânico de revestimentos cerâmicos ou porcelanatos em ambientes internos são as NBR 13753 e NBR 13754 (ABNT, 1996), para pisos e paredes, respectivamente. Ainda que sejam normas prescritivas para avaliação de assentamento com materiais cimentícios, fez-se a aplicação de peças cerâmicas do grupo de absorção BIIb, com faixa de absorção entre $6 \%$ e 10\%, para simulação de condições de obra e realização do ensaio de tração simples em arrancamento a posteriori.

São normas distintas, em função das peculiaridades das aplicações em paredes e pisos, entretanto, o Anexo A das duas normativas, que prescreve a metodologia de avaliação de desempenho mecânico por meio da aplicação de uma força de tração simples é compartilhado. Neste trabalho seguiu-se as prescrições deste documento.

A aplicação se procedeu em um substrato de contrapiso de argamassa em um ambiente interno, sem exposição à chuva e ao sol, por se tratar de uma avaliação em ambientes internos. Fez-se a aplicação sem dupla colagem, ainda que as peças apresentem área superior a $900 \mathrm{~cm}^{2}$, porque tratase de uma especificação do fabricante do composto polimérico, justificada pela EN 12004-1 (BS, 2017), que estabelece os procedimentos para aplicação de produtos não cimentícios no assentamento de revestimentos; e exige a aplicação de produto em no mínimo $10 \%$ da área total da peça.

A Figura 4 (a), (b) e (c) mostra, respectivamente, o processo de aplicação do produto com desempenadeira dentada de $8 \mathrm{~mm}$, em que fez-se o espalhamento do composto sobre o substrato com o lado liso da ferramenta, e após fez-se a formação dos cordões com o lado dentado, a temperatura no momento de aplicação foi registrada em $29^{\circ} \mathrm{C}$ e o consumo medido foi de $5,5 \mathrm{~kg} / \mathrm{m}^{2}$; a amostra finalizada já com a aplicação de rejunte cimentício após 3 dias do assentamento; e 28 dias após o assentamento já com as pastilhas metálicas de arrancamento para realização do ensaio.

Figura 4: preparação dos corpos de prova para tração simples em simulação de obra segundo a ABNT NBR 13753:1996. (a) aplicação do composto polimérico para assentamento de peças cerâmicas em contrapiso de argamassa, (b) aplicação finalizada com rejuntamento e (c) colagem de pastilhas metálicas para arrancamento. 

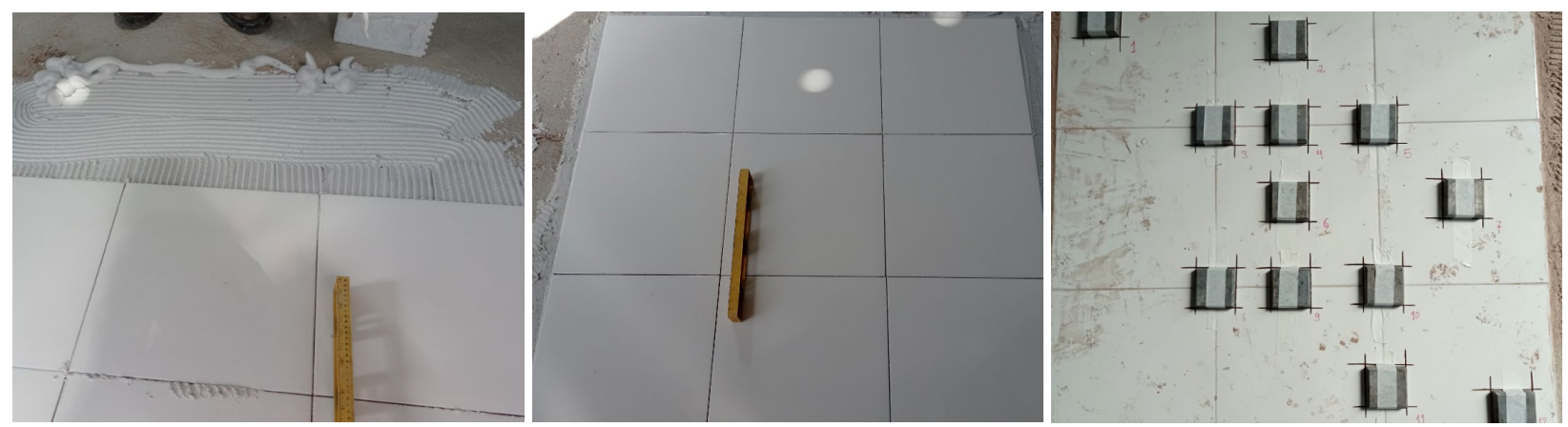

Fonte: registrado pelos autores.

Os corpos de prova foram cortados aos 27 dias e fez-se a colagem com adesivo epóxi bicomponente das pastilhas metálicas $10 \times 10 \mathrm{~cm}$, aos 28 dias fez-se o tracionamento dos corpos de prova com equipamento Solotest de arrancamento, em que a força é medida com dinamômetro digital e as áreas unitárias exatas dos corpos de prova foram medidas com paquímetro digital. $\mathrm{O}$ posicionamento dos corpos de prova foi definido aleatoriamente, com a disposição em juntas, em regiões periféricas e em regiões centrais das peças cerâmicas.

\section{APRESENTAÇÃO E DISCUSSÃO DE RESULTADOS}

Neste item estão sendo apresentados os resultados e a correspondente discussão de resultados obtidos no programa experimental deste trabalho.

\subsection{Resultados de Cisalhamento segundo a ISO 13007:2014}

O gráfico da Figura 5 apresenta os resultados dos ensaios de resistência ao cisalhamento nas diferentes condições de exposição das amostras, inclusive no método de imersão que se dá para a categoria de requisitos para compostos poliméricos de ambientes externos. É possível observar que o composto polimérico avaliado apresentou $1,72 \mathrm{MPa}$ de resistência ao cisalhamento na média de resultados do ensaio em secagem ambiente; e 1,52 MPa na média dos valores de secagem ambiente e posterior exposição à temperatura elevada em estufa, ambos atendendo ao critério mínimo de 1,0 MPa de resistência.

Nota-se ainda que para a condição de secagem ambiente os resultados apresentaram uma variação bastante restrita, indicando uma uniformidade de comportamento ao esforço de cisalhamento, diferentemente do que normalmente se observa em ensaios de tração simples, em que os resultados podem apresentar coeficiente de variação de até $60 \%$ em uma mesma amostra, conforme Lordsemm et al (1997). Os resultados para o método de temperatura elevada não apresentaram-se com a mesma baixa variação, provavelmente porque existe a formação de microfissuras na matriz do composto polimérico que reduz a padronização de dados. 
Figura 5: resultados de cisalhamento segundo o método da ISO 13007:2014

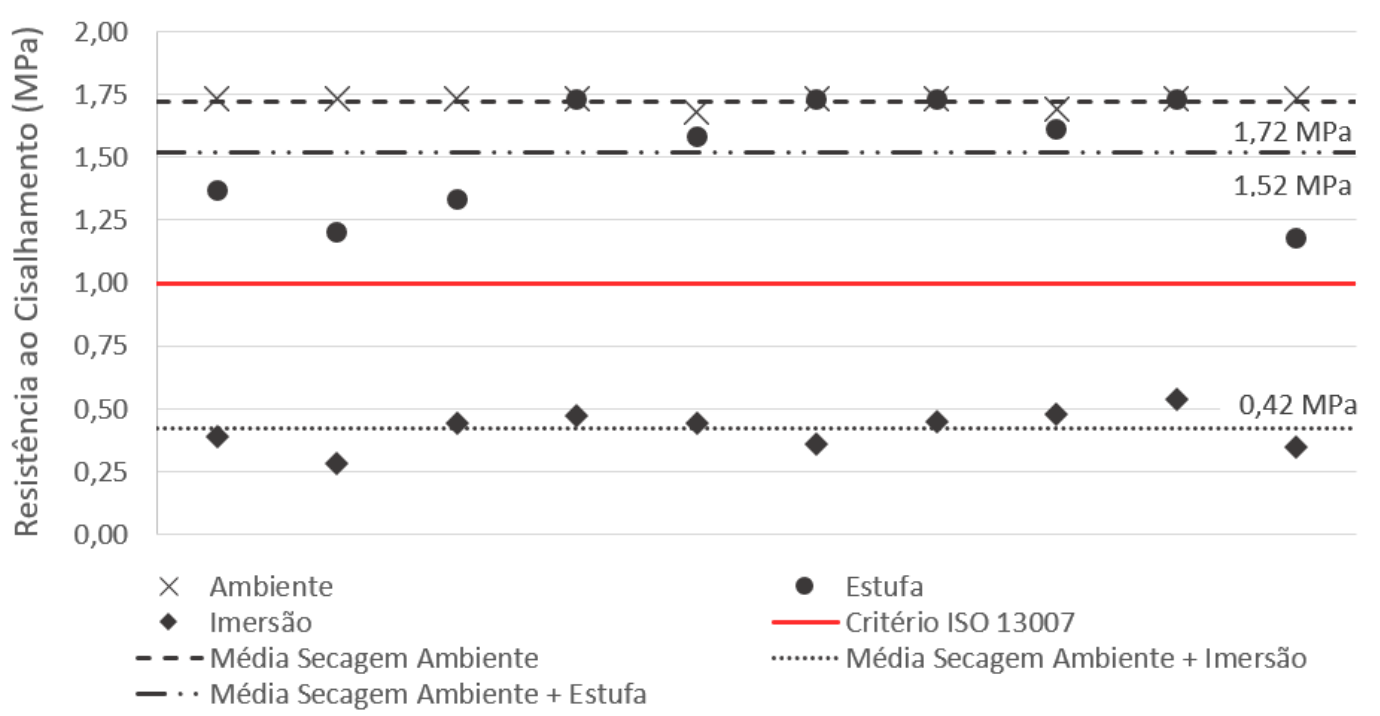

Fonte: elaborado pelos autores.

O teste de imersão foi realizado como um ensaio complementar neste estudo, como já dito, visto que não é um critério para a categoria $\mathrm{D} 1$. O valor da média resultou em $0,42 \mathrm{MPa}$, e se compararmos com a categoria D2 da ISO 13007 (ISO, 2014), o composto avaliado atingiu 84\% do valor exigido.

\subsection{Resultados de Tração Simples segundo a ABNT NBR 14081:2012}

Na Figura 6 é apresentado o gráfico com os resultados dos ensaios de tração simples segundo a metodologia da NBR 14081 (ABNT, 2012), tanto para o método de secagem ambiente, secagem com posterior imersão e método com secagem ambiente e estufa. Diz-se secagem e não cura porque o composto polimérico não cura, mas expulsa a água da matriz.

Pode-se observar que o valor do ensaio de secagem normal é 1,16 $\mathrm{MPa}, 2,32$ vezes superior ao limite da norma. Para o ensaio de secagem com temperatura elevada o resultado foi de $0,59 \mathrm{MPa}$, atendendo-se o critério mínimo de $0,5 \mathrm{MPa}$, ainda que estes ensaios e requisitos não sejam definidos para compostos poliméricos. A variação dos resultados é significativamente superior às variações observadas no ensaio de cisalhamento. Isso ocorre porque provavelmente no cisalhamento as tensões são dissipadas de maneira mais homogênea, e no fenômeno de tração simples ocorre a aplicação direta de tensão sobre uma pequena espessura de material colante, nesse caso o composto polimérico.

No teste de imersão os resultados de resistência de aderência à tração simples foram, na média, 0,09 MPa, não atendendo ao requisito da norma. Todavia, é conhecido que as condições de ensaio dessa norma são definidas para a tecnologia cimentícia, sendo que esta reage quimicamente com a água para formação dos compostos resistentes e, consequentemente, aumento das propriedades de desempenho mecânico; já os compostos poliméricos necessitam passar pelo processo físico de secagem para atingirem as suas propriedades finais, sendo prejudicados por essa avaliação, contrariamente aos materiais cimentícios. 
Figura 6: resultados de tração simples em laboratório segundo o método da ABNT NBR 14081:2012

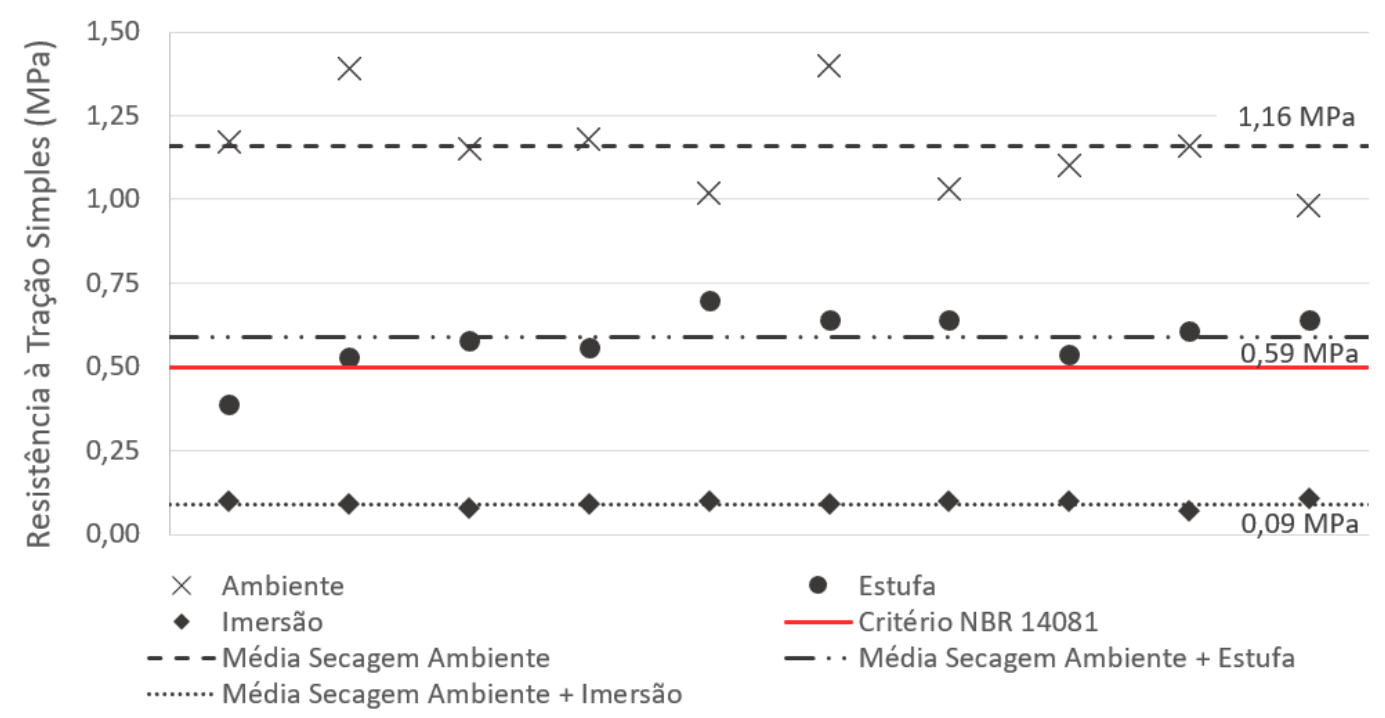

Fonte: elaborado pelos autores.

\subsection{Resultados de Tração Simples segundo as ABNT NBR 13753:1996 e NBR 13754:1996}

Os resultados de resistência de aderência à tração simples pelo método prescrito no Anexo A das NBR 13753 e NBR 13754 (ABNT, 1996), que se deu na aplicação de peças cerâmicas para simulação de obra, são apresentados na Figura 7, em que se observam também a média dos resultados unitários e o critério estabelecido pelas referidas normas técnicas. Como visto no item 2.2.3, o critério é dado em um nível de tensão de $0,3 \mathrm{MPa}$ para 4 amostras em 6 que foram submetidas ao esforço de tração. Neste trabalho foram realizados 12 arrancamentos, e, portanto, 8 corpos de prova seriam o critério proporcional ao método prescritivo das normas. Neste método existem resultados somente para condição de secagem ambiente, visto que se trata de uma simulação de obra.

Figura 7: resultados de tração simples em simulação de obra pelo método das ABNT NBR 13753 e NBR 13754

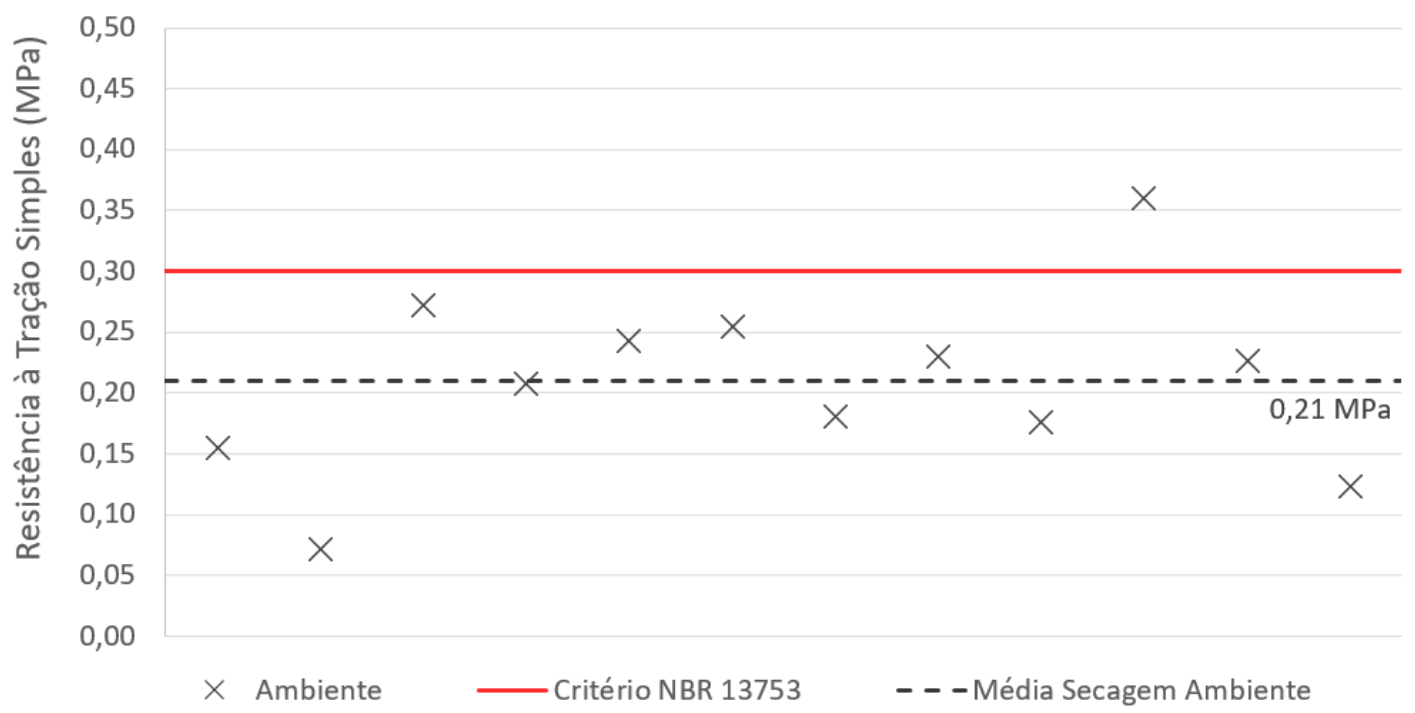

Fonte: elaborado pelos autores. 
Observa-se que somente uma amostra atingiu o critério, com 0,36 MPa de resistência de aderência à tração simples. A média geral de resultados foi de $0,21 \mathrm{MPa}$, exatamente $70 \%$ do valor de critério. Para um esforço de tração simples, cujo fenômeno não é verificado de forma isolada na prática, como já definido, trata-se de uma resistência relativamente elevada. Isso é dito porque para um nível de tensão de $0,21 \mathrm{MPa}$ aplicados em uma área média de $10447 \mathrm{~mm}^{2}$, como foi medido neste trabalho, corresponde a uma força média de $218 \mathrm{kgf}$.

Nesse sentido, é possível afirmar que $218 \mathrm{kgf}$ aplicados ao revestimento na forma de tração simples de arrancamento, perpendicular ao plano desse revestimento, seja de piso ou de parede, não ocorrem fenomenologicamente nos eventos de desplacamentos. Não ocorrem nem na peça inteira, menos ainda em uma área de 10 x $10 \mathrm{~cm}$. Ainda assim não pode-se dizer que o sistema avaliado em simulação de obra atingiu os requisitos das normas brasileiras para avaliação de desempenho mecânico.

\subsection{Resultados Médios Comparativos entre os Métodos Avaliados}

O gráfico da Figura 8 apresenta os resultados médios de tração simples em arrancamento, tanto para os métodos de laboratório prescritos pela NBR 14081 (ABNT, 2012) quanto para os métodos de campo na simulação de obra prescritos pelo Anexo A das NBR 13753 e NBR 13754 (ABNT, 1996), além dos resultados médios de cisalhamento para os métodos indicados para adesivos de dispersão aquosa da ISO 13007 (ISO, 2014). Além disso, são indicados no gráfico os níveis de tensão requisitados pelas normativas.

Nota-se que para o método de secagem ambiente têm-se resultados para os três métodos avaliados, e para os métodos de secagem ambiente com posterior exposição a alta temperatura em estufa e ambiente com posterior imersão em água observam-se resultados para o método de tração simples em laboratório da NBR 14081 (ABNT, 2012) e para o método de cisalhamento da ISO 13007 (ISO, 2014). Salienta-se ainda que para o método de cisalhamento com imersão das amostras é dado para adesivos de dispersão aquosa indicados para assentamento de pisos e revestimentos de paredes em ambientes externos, que não é o caso neste trabalho; por isso, trata-se de um método adaptado, somente para comparação com resultados previstos de resistência à tração simples. 
Figura 8: resultados médios comparativos entre os métodos avaliados em diferentes condições de secagem.

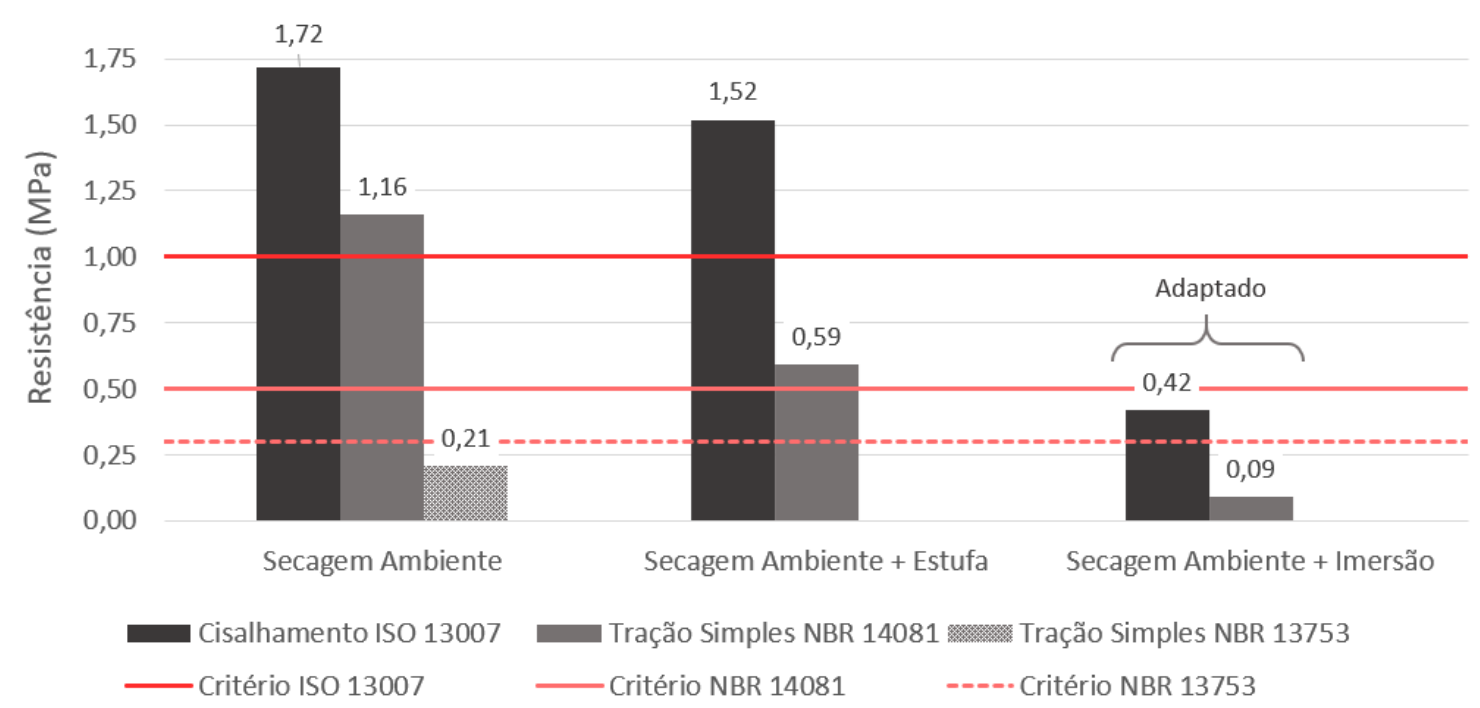

Fonte: elaborado pelos autores.

Para secagem ambiente, em que os corpos de prova permaneceram por 28 dias expostos às condições estabelecidas para ensaios de tração simples, tanto em laboratório quanto em simulação de obra, e 14 dias para o caso dos ensaios de cisalhamento, nota-se que a média de resultados de tração em simulação de obra não atingiu o critério estabelecido pelas NBR 13753 e NBR 13754 (ABNT, 1996). Entretanto, para o caso de tração simples em laboratório, a resistência média foi $232 \%$ superior ao critério normalizado. Para o caso de cisalhamento o resultado médio foi $72 \%$ superior ao critério da ISO 13007 (ISO, 2014).

É importante observar que o nível de tensão de cisalhamento exigido é o dobro do requerido para tração simples na norma brasileira. Os resultados mais baixos na simulação de obra devem estar associados às inúmeras variáveis impostas pelas condições não controladas de exposição durante os 28 dias de secagem, de execução do substrato e de aplicação por meio da mão de obra. Além disso, como o composto polimérico depende da expulsão de água da matriz para desenvolvimento de aderência, os resultados indicam que em condições laboratoriais esse fenômeno é mais facilitado, tanto pelos tamanhos dos corpos de prova quanto pelo controle de temperatura e umidade. Ainda assim, como já explorado no item 3.3, 0,21 MPa de tensão aplicados em tração simples não são condições normalmente verificadas na realidade, porque conforme Llorens et al. (2020), Silva (2018) e Souza et al. (2018), sabemos que a principal causa de desplacamentos é o esforço de cisalhamento.

Para a condição de secagem em estufa, que é dada após um período de exposição às condições ambientes controladas, os resultados, tanto de cisalhamento quanto de tração simples, atingiram os critérios estabelecidos. Para o caso de cisalhamento, a média foi 52\% superior; para tração simples foi de $18 \%$ acima do exigido. Essa redução de resistência quando comparada com o método de exposição ambiente unicamente pode estar associada à redução de aderência química, por exemplo, ou à formação de microfissuras na matriz a partir da expulsão acelerada de água. Ainda assim, mais uma vez, atingiu resultados acima dos limites estabelecidos.

Nota-se que na condição de exposição ambiente com posterior imersão dos corpos de prova os resultados não atingiram os critérios normativos. No ensaio de cisalhamento o nível de tensão 
atingido foi de $84 \%$ do nível mínimo exigido, isso porque para compostos poliméricos de ambientes externos a ISO 13007 (ISO, 2014) estabelece que o critério para o método de imersão é de $0,5 \mathrm{MPa}$. Já para tração simples, o resultado médio foi $18 \%$ em relação ao exigido. Entretanto, como já dito, a ISO 13007 (ISO, 2014) não prescreve um método de imersão para compostos poliméricos de dispersão aquosa indicados para ambientes internos. Daí a afirmação de que tratase de um método adaptado para as condições de avaliação deste trabalho.

A NBR 14081 (ABNT, 2012) é uma normativa indicada para avaliação de materiais cimentícios, e, portanto, a imersão em água das amostras favorece a formação dos compostos resistentes provenientes da hidratação do cimento, e não cria uma condição crítica de avaliação. Para compostos de dispersão aquosa esse método atua de forma inversa, porque gera ao sistema avaliado condições de impedimento para a expulsão da água de sua matriz. Ainda assim, no ensaio de cisalhamento o resultado foi positivo, com atingimento de $84 \%$ do critério normativo, tendo que não é um produto para ambientes externos.

Isso ocorreu provavelmente porque materiais poliméricos tendem a ser significativa e expressamente mais flexíveis do que materiais cimentícios, ainda que tenham adição de polímeros em baixo teor. Essa flexibilidade permite a dissipação de tensões de cisalhamento maior do que a dissipação de tensões de tração simples, porque na tração simples a dissipação ocorre na espessura da camada do material colante, e no cisalhamento a dissipação ocorre em toda a interface de adesão. Aqui é importante salientar que não se afirma que a aplicação da tensão não seja na interface no caso da tração simples, mas que a dissipação da energia se dá em condições geométricas mais limitadas, neste caso limitadas à espessura.

\section{CONSIDERAÇÕES FINAIS}

Este trabalho teve por objetivo explorar as diferenças entre os fenômenos de tração simples e cisalhamento nos eventos de desplacamentos e avaliar os métodos de medição de desempenho mecânico em compostos poliméricos de dispersão aquosa, além de observar a existência ou não de uma metodologia mais adequada para esse tipo de material, não cimentício. As principais considerações finais a serem realizadas a partir do exposto são:

- A ISO 13007 (ISO, 2014) parece apresentar a metodologia de ensaio mais adequada para enquadramento normativo de compostos poliméricos de dispersão aquosa. Não somente porque especifica um processo de avaliação especificamente para esse material, mas porque avalia justamente o principal esforço mecânico atuante nos sistemas de revestimentos, que é o cisalhamento. Além disso, as normas brasileiras prescritivas para materiais a base de cimento estabelecem um método também de imersão, mesmo para avaliação de sistemas em ambientes internos; mas como visto, para adesivos de dispersão aquosa de qualquer natureza esse não é um processo que favorece o comportamento do produto, diferentemente do verificado para materiais cimentícios;

- Ainda que o sistema de revestimento seja construído com materiais cimentícios, é provável que uma avaliação da resistência de aderência em cisalhamento seja também mais adequada, porque esse é o principal fenômeno atuante em situações reais, como observado por mais de um autor. Esse método ainda potencializa a uniformidade de resultados unitários e permite a avaliação real do desempenho mecânico;

- O composto polimérico avaliado nesta pesquisa, portanto, atende aos requisitos estabelecidos pela norma técnica associada à tecnologia, além de atender aos métodos sem imersão na NBR 14081 (ABNT, 2012) e se comportar em tração simples com mais de 2/3 
do nível exigido para normas de avaliação in situ, para materiais cimentícios, salienta-se. Por se tratar de um material flexível, como afirmado por outros autores e pela própria ISO 13007 (ISO, 2014), o composto polimérico estudado, a partir dos resultados obtidos, apresenta potencial de absorver as deformações por dilatação térmica diferencial e efeitos dinâmicos das edificações, e, portanto, potencial de eliminar as manifestações patológicas de sistemas de revestimentos no que se refere aos desplacamentos.

\section{REFERÊNCIAS BIBLIOGRÁFICAS}

Associação Brasileira de Normas Técnicas. (1996). NBR 13753: Revestimento de piso interno ou externo com placas cerâmicas e com utilização de argamassa colante-Procedimento. Rio de Janeiro.

Associação Brasileira de Normas Técnicas. (1996). NBR 13754: Revestimento de paredes internas com placas cerâmicas e com utilização de argamassa colante - Procedimento. Rio de Janeiro.

Associação Brasileira de Normas Técnicas. (2012). NBR 14081: Argamassa colante industrializada para assentamento de placas cerâmicas - Requisitos. Rio de Janeiro.

Associação Brasileira de Normas Técnicas. (2020). ISO NBR 13006: Placas cerâmicas Definições, classificação, características e marcação. Rio de Janeiro.

Associação Brasileira de Normas Técnicas. (2020). NBR 8877: Adesivos - Determinação do teor de sólidos. Rio de Janeiro.

Associação Brasileira de Normas Técnicas. (2020). NBR 8916: Adesivos e selantes Determinação da massa específica - Método picnômetro. Rio de Janeiro.

Bauer, E., Castro, E. K., Leal, F. E., Antunes, G. R. (2011). "Identification and quantification of failure modes of new buildings facades in Brasilia" in: Proceedings of XII International Conference on Durability of Building Materials and Components, FEUP Edições, Porto (Portugal), pp. 1089-1096.

Bauer, R. J. F., Rago, F. (2001), Normalização de argamassas colantes para assentamento e argamassas para rejuntamento de placas cerâmicas. Ambiente Construído. 2: 81-84.

British Standard - European Standard. (2008). EN 12002: Adhesives for ceramic tiles: Determination of transverse deformation for cementitious adhesives and grouts. Londres.

British Standard - European Standard. (2017). EN 12004-1: Adhesives for ceramic tiles. Requirements, assessment and verification of constancy of performance, classification and marking. Londres.

British Standard (2013). BS 4551: Mortar. Methods of test for mortar and screed. Chemical analysis and physical testing. Londres.

Câmara Brasileira da Construção Civil - CBIC. (2019). https://cbic.org.br/es_ES/entrevistadesplacamento-ceramico-construcao-civil-defende-rapida-resolucao/. Último acesso em 24/05/2021.

Cincotto, M. A. Silva. Carasek, H. (1995). Argamassas de revestimento: propriedades, características e métodos de ensaios. IPT - Instituto de Pesquisas Tecnológicas. 118p. São Paulo. 
Internation Organization for standardization. (2014). ISO 13007: Ceramic tiles - grouts and adhesives. Genebra.

Llorens, J., Llorens, M., Chamorro, M. A., Gómez, J., Barris, C. (2020), Experimental study on the vertical interface of thin-tile masonry. Construction and Building Materials. 261:1-11.

Lordsleem, A., Souza, J., Medeiros, J., Sabbatini, F. (1997). "Resistência de aderência de revestimentos cerâmicos". in: Anais do Simpósio Brasileiro de Tecnologia de Argamassas, 259270.

Lourenço, T., Matias, L., Faria, P. (2017), Anomalies detection in adhesive wall tiling systems by infrared thermography. Construction and Building Materials. 148:419-428.

Mehta, P. K.; Monteiro, P. J. M. (2014), "Concreto: Microestrutura, Propriedades e Materiais". $2^{0}$ ed. IBRACON, São Paulo, Brasil.

Melo, A. C. Costa e Silva, A. J. Torres, S. M. Delgado, J.P.M.Q. Azevedo, A.C. (2020), Influence of the contact area in the adherence of mortar-Ceramic tiles interface. Construction and Building Materials. 243:1-14.

Oliveira, P. V., Neves, R. R., Moreira, G. A. M., Santos, W. J., Carvalho Júnior, A. N. (2019). "Desplacamento de revestimento cerâmico interno no sistema construtivo parede de concreto moldado in loco" in: Anais do VI Congresso de Engenharia Civil, UFJF, Juiz de Fora, (Brasil), pp. s/n.

Sagave, A. M. (2001), "Desenvolvimento de método de ensaio de aderência ao cisalhamento de peças cerâmicas de revestimento", Dissertação de Mestrado, Universidade Federal de Santa Catarina.

Sassaki, C. H. F. (2017), "Avaliação dos fatores de desplacamento de revestimentos cerâmicos em fachadas de edificios na cidade de Curitiba - PR”, Monografia de especialização.

Universidade Tecnológica Federal do Paraná.

Silva, A. C. M. (2018), "Contribuição ao estudo da influência da área de contato na aderência da interface argamassa colante-cerâmica”, Dissertação de Mestrado, Universidade Católica de Pernambuco.

Souza, J. Silva, A. Brito, J. Bauer, E. (2018), Service life prediction of ceramic tiling systems in Brasília-Brazil using the fector method. Construction and Building Materials. 192: 38-49.

Souza, J. Silva, A. Brito, J. Bauer, E. (2018), Service life prediction of ceramic tiling systems in Brasília-Brazil using the fector method. Construction and Building Materials. 192: 38-49.

Wetzel, A. Zurbriggen, R. Herwegh, M. Greminger, A. Kaufmann, J. (2012), Long-term study on failure mechanisms of exterior applied tilings. Construction and Building Materials. 37: 335-348.

Winnefeld, F. Kaufmann, E. Hack, E. Harzer, S. Wetzel, A. Zurbriggen, R. (2012), Moisture induced lenght changes of tile adhesive mortars and their impact on adhesion strenght.

Construction and Building Materials. 30:426-438. 